\title{
PERENCANAAN STRATEGIK SBU MINERAL PT SUCOFINDO (PERSERO)
}

\section{Suprapto $^{*}$, , Lukman M. Baga ${ }^{* * *}$, dan Kirbrandoko $\left.{ }^{* * *}\right)$}

${ }^{*}$ PT. Sucofindo (Persero)

Graha Sucofindo Lt. 1, Jl. Raya Pasar Minggu Kav. 34, Jakarta 12780

**) Departemen Agribisnis, Fakultas Ekonomi dan Manajemen, Institut Pertanian Bogor

Jl. Kamper Kampus IPB Darmaga, Bogor 16680

$\left.{ }^{* * *}\right)$ Pascasarjana Universitas Ibn Khaldun

Jl. K.H. Sholeh Iskandar Km. 2 Bogor 16162

\begin{abstract}
Strategic planning requires an organization in the face of today's business competition and a more complex future. Likewise, Mineral Gas Station also requires this strategic planning as a newly formed business unit of 2015. Therefore, the company analyzed its internal and external factors as well as a future review of the mineral service industry to stay afloat, grow and develop. The objectives of this study were to identify the internal performance and core competencies of Mineral Gas Station, to identify the external macro environment condition and external micro intensity of mineral service industry competition, to map the current position of the company, to recommend appropriate business strategy in facing competition pressure, and to develop the objectives and program of the company. This research used descriptive and quantitative analysis methods with a purposive sampling technique. The results show that the position of Mineral Gas Station on the intensity of mineral service competition is 'moderate' and is in quadrant of 'grow and build'. Therefore, the appropriate strategy is intensive strategy (market penetration, market development and product development). Mineral Gas Station require to conduct customer satisfaction surveys related to customer perspectives which becomes the most important strategic factor with a focus on customer complaint factor. Further research is needed by involving all external parties so that the results will be more independent.
\end{abstract}

Keywords: mineral services, strategic planning, competition, mineral gas station, Sucofindo

\begin{abstract}
ABSTRAK
Perencanaan strategik dibutuhkan organisasi dalam menghadapi persaingan bisnis saat ini dan masa depan yang semakin komplek. Demikian juga yang dibutuhkan SBU Mineral sebagai unit bisnis yang baru terbentuk 2015, dengan menganalisis faktor internal dan ekternal perusahaan serta tinjauan masa depan industri jasa mineral untuk tetap bertahan, tumbuh dan berkembang. Tujuan penelitian ini adalah untuk mengidentifikasi kinerja internal dan kompetensi inti SBU Mineral, mengidentifikasi kondisi lingkungan eksternal makro dan eksternal mikro intensitas persaingan industri jasa mineral, memetakan posisi SBU Mineral saat ini dan merekomendasikan strategi bisnis yang tepat dalam menghadapi tekanan persaingan serta menyusun tujuan dan program SBU Mineral. Penelitian ini menggunakan metode analisis deskriptif dan kuantitatif dengan teknik purposive sampling. Hasil penelitian menunjukkan bahwa posisi SBU Mineral pada intensitas persaingan jasa mineral 'tingkat sedang' serta berada pada kuadran 'tumbuh dan membangun'. Oleh sebab itu, strategi yang tepat adalah stretegi intensif (penetrasi pasar, pengembangan pasar dan pengembangan produk). SBU Mineral perlu melakukan survei kepuasaan pelanggan terkait dengan perspektif pelanggan yang menjadi faktor strategis paling penting dengan fokus pada faktor keluhan pelanggan. Diperlukan penelitian lebih lanjut dengan melibatkan semua responden dari pihak eksternal sehingga hasil yang diperoleh akan lebih independen.
\end{abstract}

Kata kunci: jasa mineral, perencanaan strategik, persaingan, SBU mineral, Sucofindo

\footnotetext{
${ }^{1}$ Alamat Korespondensi:

Email: prapto_jyp@yahoo.com.sg
} 


\section{PENDAHULUAN}

Industri pertambangan masih merupakan industri yang menarik dan menjanjikan bagi dunia bisnis dalam upaya ikut berperan dalam meningkatkan pendapatan secara nasional. Pendapatan negara dan dari sektor minerba (mineral dan batubara) sepanjang tahun 2014, berhasil menyumbang pendapatan negara Rp34,2 triliun (Dirjen Minerba ESDM, 2014). Nilai tersebut masih di bawah target pemerintah, yaitu sebesar Rp39,6 triliun. Namun, diatas realisasi 2013 yang hanya Rp28,4 triliun. Sebaliknya, perkembangan ekspor mineral dua tahun terakhir seperti pada Tabel 1.

Terdapat penurunan secara kuantitas ekspor, akibat adanya regulasi berupa Undang-Undang Minerba No.4 Tahun 2009 dan Permen ESDM No.7 Tahun 2012, disebutkan pemerintah mendorong adanya ekspor mineral yang mempunyai nilai tambah. Dengan menurunnya jumlah ekspor mineral jelas berpengaruh pada dunia bisnis sektor mineral dan berpengaruh juga pada Strategic Business Unit (SBU) Mineral sebagai salah satu pelaku bisnis penyedia jasa mineral. Munculnya era perdagangan bebas merupakan tantangan bagi Indonesia, karena tidak memiliki pilihan selain harus ikut serta di dalamnya (Lina, 2012).

Secara umum dapat dipahami bahwa ada faktor yang mendorong perubahan dunia, yaitu teknologi dan globalisasi (Sadikin et al. 2010). Kebijakan politik, pemerintahan, dan perundang-undangan dapat mewakili peluang dan ancaman penting bagi perusahaan skala besar maupun kecil (David, 2011).
Menyikapi situasi dan kondisi seperti di atas SBU Mineral PT. Sucofindo sebagai pihak ketiga penyedia jasa mineral yang mandiri dan independen, siap mendukung kebijakan pemerintah, melalui penyediaan jasa produk mineral, dengan menyusun perencanaan strategik ke depan. Produk jasa yang dihasilkan berupa sertifikat/laporan menjadi hal penting dalam memberikan kepercayaan pelanggan baik nasional maupun internasional.

Sertifikat sebagai alat untuk menembus pasar internasional merupakan dokumen yang menyatakan suatu produk/jasa sesuai dengan persyaratan standar atau spesifikasi teknis tertentu seperti yang dikatakan (Widyastutik dan Reni, 2013). Dalam pelaksanaan strategi diperlukan sistem kontrol strategis yang dapat memastikan strategi dapat di terjemahkan ke dalam tindakan atau implementasi (Atkinson, 2006). Untuk itu diperlukan suatu strategi bersaing yang efektif dan efisien sehingga dapat memberikan keuntungan bagi perusahaan dan memberikan keunggulan bersaing (David, 2011). Sebaik apapun strategi yang akan dijalankan, tetapi tanpa adanya suatu tujuan yang jelas, maka strategi tersebut tidak akan berjalan dengan efektif (Ireland RD et al. 2008). Penelitian Saunders et al. (2008) menyimpulkan terdapat variasi 50 praktek implementasi strategi dalam hal soft dan hard implementation. Sebagai contoh seperti dalam penelitian (Otto, 2016) yang menyatakan bahwa strategi pengembangan pasar, yaitu dengan fokus memasarkan kategori-kategori tersebut pada daerah-daerah yang masih memberikan keuntungan, naikkan anggaran iklan dan promosi penjualan pada daerah-daerah tersebut.

Tabel 1. Ekspor komoditi hasil pertambangan mineral (Jan-Okt, 2014-2015)

\begin{tabular}{lrrrrrr}
\hline \multirow{2}{*}{ Jenis Barang } & \multicolumn{2}{c}{ Berat Bersih ( Ton ) } & Perubahan & \multicolumn{2}{c}{ Nilai FOB ( Ribu US ) } & Perubahan \\
\cline { 2 - 7 } & \multicolumn{1}{c}{ Jan-Okt'14 } & Jan-Okt'15 & \multicolumn{1}{c}{$\%$} & Jan-Okt'14 & Jan-Okt'15 & $\%$ \\
\hline Total Pertambangan & 352.670 .707 & 318.641 .014 & $-10,59$ & 18.975 .397 & 16.496 .938 & $-13,06$ \\
Biji Tembaga & 468.057 & 1.369 .243 & 19,254 & 1.161 .901 & 2.701 .707 & 132,52 \\
Biji Nikel & 460.121 & 0 & $-100,00$ & 85.913 & 0 & $-100,00$ \\
Bauksit & 2.086 .673 & 2.212 & $-99,89$ & 46.779 & 675 & $-98,56$ \\
Bijih Timah /TIN & 0 & 20 & - & 0 & 9 & - \\
Batu Bara & 338.218 .240 & 305.986 .816 & $-9,53$ & 17.502 .671 & 13.633 .041 & $-22,11$ \\
Granit & 48.523 & 0 & $-100,00$ & 344 & 1 & $-99,81$ \\
Pasir Alam & 0 & 0 & 0 & 0 & 0 & 0 \\
Tambang Lainnya & 11.389 .093 & 11.282 .723 & $-0-93$ & 177.789 & 161.505 & $-9,16$ \\
\hline
\end{tabular}

Sumber: Buletin Statistik Perdagangan Luar Negeri (BPS,2015) 
Manajemen strategik dapat didefinisikan sebagai suatu seni dan ilmu untuk memformulasikan, menerapkan, dan mengevaluasi keputusan lintas fungsi yang memungkinkan suatu organisasi mencapai tujuannya (David, 2011). Analisis kinerja menjadi salah satu analisis faktor internal organisasi yang dapat dilakukan dengan melakukan pendekatan dengan metode Balanced Scorecard (BSC) seperti yang dikatakan Kaplan dan Norton (2008) bahwa mula-mula BSC digunakan untuk memperbaiki sistem analisis kinerja eksekutif. Keunggulan manajemen berbasis kinerja adalah penentuan sasaran organisasi yang jelas dan terarah (Ika et al. 2012).

Empat perspektif dalam BSC adalah keuangan, pelanggan, proses bisnis internal serta pembelajaran dan pertumbuhan. Keunggulan pendekatan BSC dalam sistem perencanaan strategis (Mulyadi, 2007), adalah mampu menghasilkan rencana strategis, yang memiliki karakteristik sebagai komprehensif, koheren, berimbang dan terukur. BSC lebih dimanfaatkan sebagai alat yang efektif untuk perencanaan strategik, berfungsi sebagai alat untuk menerjemahkan visi, misi, tujuan, keyakinan dasar, nilai dasar dan strategi organisasi ke dalam rencana tindakan (action plans) yang komprehensif, koheren, berimbang dan terukur (Adriana, 2008).

Kompetensi inti didefinisikan sebagai sesuatu yang dilakukan oleh sebuah perusahaan lebih baik dari yang dilakukan oleh perusahaan lainnya (Russel dan Taylor, 2013). Apabila perusahaan mampu memanfaatkan sumber daya dan kapibilitas untuk mengembangkan kompetensi intinya maka tidak berarti bahwa perusahaan tersebut mampu mempertahankan keberlangsungannya (Wheelen dan Hunger, 2006). Untuk dapat dikatakan kompetensi inti, kompetensi inti harus memenuhi tiga syarat, yaitu nilai bagi pelanggan, keunikan bersaing, dapat diperluas (Wheelen dan Hunger, 2006). Setiap organisasi bisnis memiliki karakteristiknya sendiri berdasarkan jenis industrinya (Ika, 2012).

Faktor lingkungan eksternal organisasi seperti kondisi eksternal makro dan mikro dapat digunakan sebagai pertimbangan analisis dalam penyusunan perencanaan strategik. Faktor lingkungan eksternal makro meliputi politik, ekonomi, sosial dan teknologi (PEST). Analisis PEST adalah analisis terhadap faktor lingkungan eksternal bisnis yang meliputi bidang teknologi, ekonomi, sosial dan teknologi (Ward dan Peppard, 2002).
Tujuan strategi bersaing suatu unit usaha di dalam sebuah industri adalah unit usaha dapat melindungi dirinya dengan sebaik-baiknya terhadap tekanan persaingan atau dapat memengaruhi tekanan tersebut secara positif. Dalam five forces model harus diketahui ada lima kekuatan yang menentukan karakteristik suatu industri, yaitu intensitas persaingan antar pemain yang ada saat ini, ancaman masuk pendatang baru, ancaman produk pengganti, kekuatan tawar menawar pemasok dan kekuatan tawar pembeli (Porter, 2007).

Dengan mengetahui posisi organisasi berada di kuadran berapa dari sembilan kuadran berdasarkan pemetaan yang dilakukan David (2011) yang mengatakan bahwa matrik Internal Eksternal (IE) dapat dibagi menjadi tiga bagian besar yang berbeda-beda. Pertama, ketentuan untuk divisi-divisi yang masuk dalam sel I, II, dan IV dapat digambarkan sebagai tumbuh dan membangun. Kedua, divisi-divisi yang masuk dalam sel III, V, dan VII dapat ditangani dengan baik melalui strategi menjaga dan mempertahankan. Ketiga, ketentuan umum untuk divisi yang masuk dalam sel VI, VIII, dan IX adalah panen atau divestasi. Organisasi yang sukses dapat mencapai portofolio bisnis yang digambarkandalam posisi atau sekitar sel 1 dalam matriks IE yaitu tumbuh dan membangun.Analisis matrik IE merupakan alat perumusan strategi meringkas dan mengevaluasi kekuatan dan kelemahan utama dalam area-area fungsional bisnis, dan juga menjadi landasan untuk mengidentifikasi serta mengevaluasi hubungan di antara area tersebut (Raymond et al. 2012). Pada matriks evaluasi tersebut, faktor kekuatan, dan kelemahan ditambahkan dengan menggunakan metode pembobotan paired comparison (Dyah, 2015).

Untuk mencapai keunggulan daya saing dalam industri, diharapkan aktor aktor yang berperan didalamnya dapat memberikan keputusan yang tepat sehingga upaya dalam meningkatkan daya saing dapat tercapai (Kanya et al. 2016). Daya saing komoditas dapat dilihat dari dua indikator, yaitu keunggulan kompetitif dan keunggulan komparatif(Jauhar dan Heny, 2012). Selain itu pemetaan posisi persaingan perusahaan juga dapat dilakukan dengan analisis kesenjangan (Thompson dan Strickland, 2006). Analisis kesenjangan adalah membandingkan antara kondisi yang harus dilakukan perusahaan untuk bersaing dengan kondisi aktual yang saat ini dilakukan perusahaan. 
Sebagai sebuah unit bisnis yang baru terbentuk pada 2015, SBU Mineral memerlukan perencanaan strategik dalam menghadapi persaingan dan tantangan bisnis. Oleh karena itu, diperlukan identifikasi dan evaluasi kekuatan dan kelemahan serta identifikasi kompetensi inti yang dimiliki. Dalam hal ini, diperlukan identifikasi dan evaluasi peluang dan ancaman yang dihadapi dalam persaingan industri penyedia jasa mineral. Hasil dari identifikasi dan evaluasi kekuatan, kelemahan, peluang dan ancaman serta identifikasi kompetensi inti yang dimiliki akan memberikan gambaran posisi saat ini SBU Mineral dalam persaingan bisnis penyedia jasa mineral. Dengan demikian, dalam menghadapi kondisi di masa depan seperti yang diinginkan, diperlukan penyusunan tujuan/sasaran dan program SBU Mineral jangka menengah lima tahunan (2016-2020) yang tepat dan sesuai agar bisa bertahan, tumbuh dan berkembang serta berkelanjutan.

Berdasarkan latar belakang tersebut dan beberapa penelitian perencanaan strategik sebelumnya, dimana penelitian ini merupakan penelitian awal di SBU Mineral PT.Sucofindo maka tujuan penelitian ini adalah mengidentifikasi kinerja internal dan kompetensi inti SBU Mineral, mengidentifikasi kondisi lingkungan eksternal makro dan lingkungan eksternal mikro intensitas persaingan industri jasa mineral, memetakan posisi SBU Mineral saat ini dan merekomendasikan strategi bisnis yang tepat untuk diterapkan dalam menghadapi tekanan persaingan dan menyusun tujuan/ sasaran dan program SBU Mineral 2016-2020.

\section{METODE PENELITIAN}

Penelitian dilakukan di unit kerja SBU Mineral PT.Sucofindo (Persero), Jl.Raya Pasar Minggu Kav.34 Jakarta. Penelitian, pengolahan data, dan penulisan tesis dilaksanakan selama tiga bulan pada Januari sampai Maret 2016. Metode yang digunakan dalam penelitian ini adalah metode deskriptif kuantitatif. Analisis deskriptif digunakan untuk menjelaskan visi dan misi (Aji et al. 2014), melalui pendekatan studi kasus dengan didahului kegiatan Focus Group Discussion (FGD) yang menekankan pada penggunaan metode analisis strategi dalam mengkaji kinerja, dengan hasil akhir dalam penelitian adalah menetapkan perencanaan strategik SBU Mineral.

Data yang digunakan dalam penelitian ini adalah data primer dan data sekunder yang bersifat kuantitatif dan kualitatif. Data primer didapatkan melalui wawancara menggunakan kuesioner kepada manajemen dan karyawan SBU Mineral serta pihak eksternal. Data sekunder diperoleh melalui data yang tersedia berupa Laporan Hasil Usaha SBU Mineral tahun 2015, data hasil survei pasar, kompetitor, literatur dan internet.

Teknik pengambilan data melalui pengambilan sampel ditentukan secara sengaja (purposive sampling dengan judgement sampling) terdiri dari responden internal, yaitu karyawan SBU Mineral yang kompeten mewakili fungsi pemasaran, operasi, pelayanan pelanggan, dan keuangan dan pihak eksternal. Responden yang dipilih terdiri dari 10 orang, yaitu Vice President, Resource and Operation Support Senior Manager, Operation Senior Manager, Sales and Marketing Manager, Mining Analysis Manager, Mineral Processing Laboratoium Manager, Support Resource Manager, Development Senior Officer dan eksternal klien (2 orang).

Teknik pengolahan data dilakukan secara analisis deskriptif dan kuantitatif dengan beberapa tahapan. Tahapan pertama mendiskripsikan visi dan misi serta mengidentifikasi kompetensi inti SBU Mineral, dilanjutkan dengan menganalisis lingkungan internal untuk mengkaji kinerja dan faktor kekuatan dan kelemahan (Internal Factors Evaluation/IFE) SBU Mineral. Selanjutnya, menganalisis lingkungan eksternal makro (Political, Economic, Social dan Technology/ PEST) untuk mengkaji faktor peluang dan ancaman (Eksternal Faktor Evaluation/EFE) SBU Mineral serta menganalisis lingkungan eksternal mikro (Five Forces Porter) untuk mengetahui tingkat persaingan bisnis jasa mineral. Hasil dari analisis eksternal dan internal akan digunakan untuk memetakan posisi SBU Mineral dalam matrik IE. Tahapan selanjutnya adalah menganalisis tinjauan masa depan industri (industry foresight) dana menganalisis kesenjangan (gap analysis) SBU Mineral. Dari beberapa tahapan yang sudah dilakukan tersebut akan digunakan untuk menyusun tujuan/sasaran dan program SBU Mineral lima tahun ke depan.

Identifikasi dan deskripsi visi dan misi dilakukan untuk melihat apakah sudah sesuai dengan keempat perpektif Balanced Scorecard (BSC) untuk melihat kinerja SBU Mineral. Hal ini senada dengan beberapa penelitian yang dilakukan oleh (Mandiangan, 2006; Ika, 2012; Dewi et al. 2014), yang menyatakan bahwa dalam menyelaraskan visi, misi, tujuan, dan strateginya kedalam suatu kerangka kerja strategis yang komprehensif, koheren,berimbang dan terukur. 
Analisis lingkungan internal melalui analisis kompetensi inti yang dimiliki saat ini dan dianggap penting untuk dikembangkan dalam upaya meningkatkan daya saing (Suswono et al. 2009). Faktor strategis internal adalah faktor-faktor kekuatan yang dapat dimanfaatkan, serta faktor-faktor kelemahan yang harus di perbaiki. Faktor strategis eksternal adalah faktor lingkungan organisasi secara keseluruhan untuk mengembangkan suatu peluang (oportunities) yang dapat dimanfaatkan organisasi dan ancaman (threat) yang harus di hindari organisasi (Suhartoyo et al. 2016).

Faktor kekuatan dan kelemahan (IFE) perusahaan dari hasil analisis dikaji dengan kerangka BSC. Selanjutnya digunakan kuesioner dalam menentukan bobot, nilai dan skor dari setiap variabel-variabel. Pembobotan dilakukan menggunakan metode paried comparison (Kinnear dan Taylor, 2003), pada Tabel 2. Skala pembobotan, yaitu $1=$ jika indikator horizontal kurang penting dari pada indikator vertikal, $2=$ jika indikator horizontal sama penting dengan indikator vertikal dan $3=$ jika indikator horizontal lebih penting dari pada indikator vetikal.

Penentuan peringkat/nilai pada faktor IFE dengan menggunakan skala peringkat $1-4$, yaitu 1 menunjukkan kelemahan tinggi, 2 kelemahan rendah, 3 kekuatan rendah, dan 4 kekuatan tinggi (David, 2011). Sedangkan aspek kompetensi inti yang dinilai (Wheelen dan Hunger, 2006) adalah aspek yang memenuhi tiga syarat tiga syarat, yaitu Customer Value/nilai bagi pelanggan), Competitor Unique/keunikan bersaing, Extendability/ dapat diperluas.

Dalam analisis faktor ekternal makro (PEST) pembobotan menggunakan metode paried comparison. Penentuan peringkat/nilai (rating) dengan menggunakan skala peringkat $1-4$, pada setiap faktor strategis,menunjukkan seberapa efektif strategi perusahaan merespon faktor ini. Peringkat 1 (merespon sangat rendah), 2 (merespon rendah), 3 (merespon tinggi), 4 (merespon sangat tinggi) (David, 2011). Dalam analisis faktor eksternal mikro intensitas ancaman persaingan industri jasa mineral pembobotan dilakukan menggunakan metode paried comparison.Penentuan peringkat/nilai (rating) dengan menggunakan skala peringkat $1-4$, pada setiap faktor strategis untuk menunjukkan seberapa efektif strategi perusahaan meresponfaktor ini. Selanjutnya ,dilakukan pengelompokan penilaian ke dalam tiga kategori, yaitu skor 1-1,99 (kategori persaingan rendah), skor 2-2,99 (persaingan sedang) dan skor 3-3,99 (persaingan tinggi).

Berdasarkan total skor IFE dan EFE, dilakukan pemetaan ke dalam matriks IE. Nilai skor IE yang diperoleh untuk mengetahui pada kuadran berapa SBU Mineral beradaakan dan menetukan formulasi strategi yang tepat untuk perusahaan. Analisis gap digunakan untuk menentukan langkah apa yang perlu diambil untuk berpindah dari kondisi saat ini ke kondisi yang diinginkan atau keadaan masa depan. yang diinginkan. Sedangkan kerangka konseptual penelitian seperti Gambar 1.

\section{HASIL}

\section{Analisis Visi dan Misi SBU Mineral}

Hasil analisis yang dilakukan terhadap visi dan misi SBU Mineral menunjukkan bahwa visi dan misi SBU Mineral telah memiliki unsur empat kerangka perspektif BSC. Hasil analisis visi dan misi berdasarkan perspektif BSC dengan hasil yang diperoleh selengkapnya pada Tabel 3.

Tabel 2. Contoh tabel penentuan bobot analisis dengan kerangka balanced scorecard dengan metode paired comparison untuk kajian kinerja perusahaan

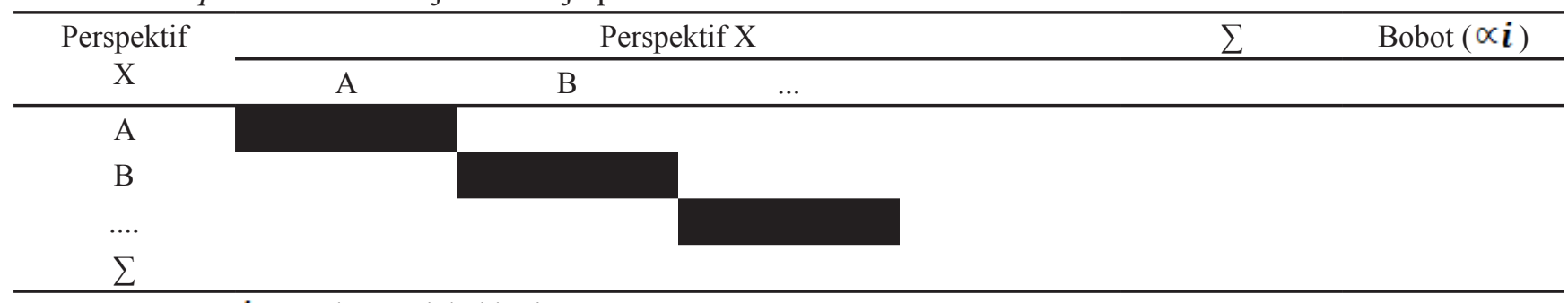

Keterangan: $\quad \propto \boldsymbol{i}=$ Bobot Variabel ke-i

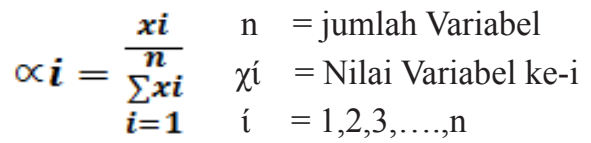




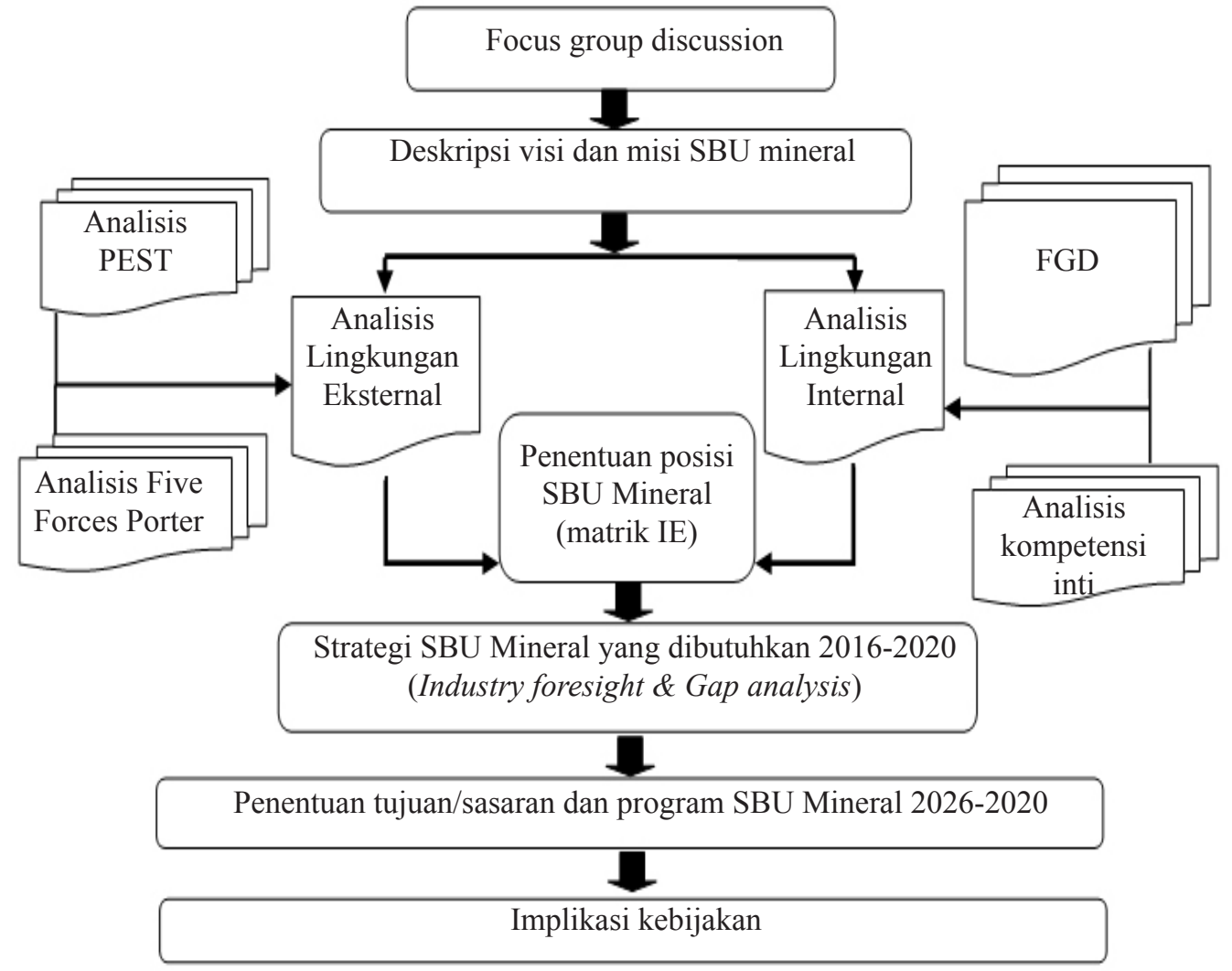

Gambar 1. Kerangka pemikiran penelitian

Tabel 3. Analisis visi dan misi SBU Mineral dalam perspektif balanced scorecard

Visi SBU MINERAL:

Menjadi SBU terpercaya dan menguntungkan dalam jasa inspeksi, supervisi, pengujian, konsultasi lima besar di wilayah ASEAN pada sektor mineral

\begin{tabular}{ll}
\hline \multicolumn{1}{c}{ Perspektif Balanced Scorecard } & \multicolumn{1}{c}{ Analisis kesesuaian Visi } \\
\hline Keuangan & Kata menguntungkan dalam jasa inspeksi, supervisi, pengujian, \\
& konsultasi \\
Pelanggan & Kata menjadi SBU terpercaya pada sektor mineral \\
Proses bisinis internal & Kata jasa inspeksi, supervisi, pengujian, konsultasi \\
Pembelajaran dan Pertumbuhan & Kata terpercaya dan lima besar di wilayah ASEAN \\
\hline
\end{tabular}

Misi SBU MINERAL:

Memberikan pelayanan prima yang memiliki nilai tambah bagi pelanggan dibidang jasa pertambangan mineral dari hulu sampai hilir, dengan berbasis IT berdasarkan budaya kerja prestasi, inovatif dan fokus pelanggan melalui peningkatan kompetensi SDM

\begin{tabular}{ll}
\hline \multicolumn{1}{c}{ Perspektif Balanced Scorecard } & \multicolumn{1}{c}{ Analisis kesesuaian Misi } \\
\hline Keuangan & Kata yang memiliki nilai tambah \\
Pelanggan & Kata fokus pelanggan \\
Proses Bisnis Internal & Kata jasa pertambangan mineral dari hulu sampai hilir, dengan \\
& berbasis IT \\
Pembelajaran dan Pertumbuhan & Kata peningkatan kompetensi SDM \\
\hline
\end{tabular}




\section{Analisis Kinerja SBU Mineral}

Untuk mengetahui kinerja SBU Mineral dilakukan analisis kinerja berdasarkan empat perspektif BSC. Keempat perspektif digunakan untuk melihat faktor yang paling penting berpengaruh terhadap kinerja SBU Mineral. Oleh karena itu, ke depan perusahaan diharapkan dapat menentukan langkah tepat dalam pengambilan kebijakannya. Analisis tersebut juga dapat digunakan sebagai bahan evaluasi berkala untuk kemajuan perusahaan. Hasil analisis yang diperoleh berasal dari responden seperti pada Tabel 4.

Hasil analisis pada Tabel 4, memperlihatkan perspektif pelanggan mendapatkan bobot yang paling tinggi yaitu 0,260 yang berarti bahwa perspektif pelanggan merupakan perspektif paling penting dan menjadi tujuan utama di SBU Mineral sebagai penyedia jasa mineral, dengan penilaian yang diberikan responden adalah 3,50 sehingga skornya paling tinggi 0,909, memperlihatkan bahwa kinerja SBU Mineral di atas optimal dalam menangani pelanggan.

\section{Indentifikasi dan Analisis Kekuatan, Kelemahan SBU Mineral}

Untuk mengetahui faktor strategis yang menjadi kekuatan dan kelemahan SBU Mineral dilakukan analisis IFE. Dalam analisis internal ini memperlihatkan berapa banyak faktor yang dimiliki SBU Mineral sebagai kekuatan dan kelemahan. Dengan mengetahui jumlah faktor strategis sebagai kekuatan dan kelemahan, diharapkan dapat membantu perusahaan dalam menentukan langkah bisnis ke depannya dengan tepat. Analisis tersebut juga dapat digunakan sebagai bahan evaluasi berkala untuk kemajuan perusahaan. Hasil analisis yang diperoleh berasal dari responden seperti pada Tabel 5 .
Hasil analisis pada Tabel 5 menunjukkan jumlah faktor kekuatan melebihi jumlah faktor kelemahan yang dimiliki. Dengan demikian, SBU Mineral secara internal memiliki kekuatan sedang yang untuk mengatasi kelemahannya (nilai rata-rata 2,9870) dengan hasil evaluasi IFE mendapatkan total skor 2,9870.

\section{Analisis Lingkungan Eksternal Mikro (Persaingan Industri)}

Untuk mengetahui tingkat persaingan jasa mineral dilakukan analisis persaingan industri. Analisis ini penting dilakukan untuk melihat persaingan bisnis jasa mineral berada pada tingkat persaingan rendah, sedang atau tinggi. Dengan mengetahui tingkat persaingan tersebut diharapkan perusahaan akan mengambil langkah yang tepat dalam menjalankan bisnis penyedia jasa mineral. Analisis tersebut juga dapat digunakan sebagai bahan evaluasi berkala untuk kemajuan perusahaan. Hasil analisis yang diperoleh berasal dari responden seperti pada Tabel 6. Hasil analisis sebagaimana Tabel 6 menunjukkan rata-rata intensitas persaingan jasa mineral berada pada tingkat sedang skor 2,8560 .

\section{Identifikasi dan Analisis Lingkungan Eksternal Makro (PEST)}

Untuk mengetahui faktor strategis yang menjadi peluang dan ancaman, dilakukan analisis PEST. Peluang dan ancaman tersebut berasal dari faktor lingkungan eksternal secara makro yang dapat memengaruhi keberlangsungan bisnis jasa mineral. Dengan mengetahui faktor peluang dan ancaman, diharapkan pesssrusahaan dapat meresponnya dengan tepat dalam menjalankan dan mempertahankan bisnisnya. Analisis tersebut juga dapat digunakan sebagai bahan evaluasi berkala untuk kemajuan perusahaan. Hasil analisis yang diperoleh berasal dari responden seperti pada Tabel 7.

Tabel 4. Hasil analisis kinerja SBU Mineral dengan balanced scorecard

\begin{tabular}{|c|c|c|c|}
\hline Jenis perspektif & Bobot & Nilai & Skor \\
\hline A. Perspektif pelanggan & 0,260 & 3,500 & 0,909 \\
\hline B. Perspektif keuangan & 0,256 & 3,500 & 0,897 \\
\hline C. Perspektif pembelajaran dan pertumbuhan & 0,244 & 3,200 & 0,781 \\
\hline D. Perspektif bisnis internal & 0,240 & 3,200 & 0,768 \\
\hline Total atau rata-rata & 1,000 & 3,350 & 3,350 \\
\hline
\end{tabular}


Tabel 5. Rekapitulasi Evaluasi Faktor Internal (IFE) SBU Mineral

\begin{tabular}{lcccc}
\hline \multicolumn{1}{c}{ Faktor strategis } & Status & Bobot & Nilai & Skor \\
\hline Produktivitas penerbitan sertifikat/laporan & Kekuatan & 0,0436 & 3,8000 & 0,1656 \\
Kecepatan penerbitan sertifikat & Kekuatan & 0,0432 & 3,6000 & 0,1554 \\
Tingkat kecermatan laporan & Kekuatan & 0,0441 & 3,5000 & 0,1544 \\
Rasio profitabilitas & Kekuatan & 0,0453 & 3,4000 & 0,1540 \\
Rasio jumlah karyawan operasi teknis (analayst, teknisi, surveyor/preparator) & Kekuatan & 0,0425 & 3,4000 & 0,1443 \\
Pelayanan dan komunikasi dengan pelanggan & Kekuatan & 0,0480 & 3,0000 & 0,1440 \\
Produktivitas kerja karyawan & Kekuatan & 0,0441 & 3,2000 & 0,1411 \\
Penilaian kinerja inspektor SBU Mineral oleh pelanggan & Kekuatan & 0,0468 & 3,0000 & 0,1403 \\
Kelengkapan sarana hardware sistem informasi & Kekuatan & 0,0422 & 3,3000 & 0,1392 \\
Kecepatan informasi kepada pelanggan & Kekuatan & 0,0447 & 3,1000 & 0,1385 \\
Optimalisasi prosedur operasional & Kekuatan & 0,0429 & 3,2000 & 0,1372 \\
Rasio aktivitas & Kekuatan & 0,0424 & 3,2000 & 0,1356 \\
Rasio jumlah karyawan non operasi teknis (tenaga administrasi/cs/sales/ & Kekuatan & 0,0410 & 3,2000 & 0,1311 \\
pencetak sertifkat/laporan/QA officer) & & & & \\
Kelengkapan sarana software IT & Kekuatan & 0,0420 & 3,1000 & 0,1301 \\
Akurasi dan kehandalan sistem informasi & Kekuatan & 0,0418 & 3,1000 & 0,1296 \\
Penilaian kinerja staf administrasi oleh pelanggan & Kekuatan & 0,0452 & 2,8000 & 0,1266 \\
Optimalisasi struktur organisasi & Kekuatan & 0,0425 & 2,8000 & 0,1189 \\
Rasio jumlah pelatihan & Kekuatan & 0,0423 & 2,7000 & 0,1141 \\
Pelatihan sesuai ruang lingkup pekerjaan karyawan dan pengembangan & Kekuatan & 0,0429 & 2,6000 & 0,1117 \\
personal & & & \\
Rasio pelanggan kontrak & Kekuatan & 0,0434 & 2,5000 & 0,1085 \\
Implementasi jasa baru & Kekuatan & 0,0413 & 2,5000 & 0,1032 \\
Rasio keluhan pelanggan & Kelemahan & 0,0437 & 2,0000 & 0,0874 \\
Rasio pelanggan spot order & Kelemahan & 0,0444 & 1,7000 & \\
& & & 0,0755 \\
\hline & & 1,0000 & 2,9870 & 2,9870 \\
\hline
\end{tabular}

Tabel 6. Hasil analisis intensitas persaingan industri jasa mineral

\begin{tabular}{lccc}
\hline \multicolumn{1}{c}{ Faktor strategis } & Total skor & Intensitas persaingan & Rangking \\
\hline Tekanan produk pengganti jasa mineral & 3,4330 & Tinggi & I \\
Persaingan antar perusahaan surveyor mineral yang ada & 3,0000 & Tinggi & II \\
Ancaman pendatang baru perusahaan surveyor mineral & 2,7500 & Sedang & III \\
Kekuatan tawar menawar pemasok (inspektor subkontraktor) & 2,7400 & Sedang & IV \\
Kekuatan tawar menawar klien perusahaan surveyor mineral & 2,3570 & Sedang & V \\
\hline Intensitas persaingan (rata-rata) & 2,8560 & Sedang & \\
\hline
\end{tabular}

Dari analisis pada Tabel 7, menunjukan SBU Mineral merespon 17 faktor strategis lingkungan eksternal makro tersebut dengan baik (nilai rata-rata 3,0882) sehingga evaluasi EFE mendapatkan total skor 3,0882.

\section{Analisis Korporat}

Untuk mengetahui keberadaan SBU Mineral di kuadran berapa dilakukan analisis matrik IE seperti pada Gambar 2. Hasil evaluasi IFE menghasilkan total skor 2,9870 yang diartikan bahwa posisi internal SBU
Mineral berada pada kategori kekuatan sedang (skor IFE 2,00-3,00). Hasil evaluasi EFE menghasilkan total skor 3,0882 yang diartikan bahwa kemampuan SBU Mineral merespon perubahan faktor eksternal peluang dan ancaman berada pada posisi tinggi (skor EFE 3,00-4,00). Berdasarkan total skor hasil evaluasi IFE dan EFE, menempatkan posisi SBU Mineral pada kuadran II (tumbuh dan membangun). Oleh karena itu, strategi yang disarankan adalah strategi intensif dengan penetrasi pasar, pengembangan pasar dan pengembangan produk. 


\section{Identifikasi Kompetensi Inti}

Terdapat tujuh kompetensi inti SBU Mineral hasil identifikasi, yaitu 1) memiliki jasa pengujian mineral prosesing yang pertama di Indonesia, 2) memiliki jaringan kerja yang luas di wilayah Indonesia, 3) memiliki tenaga verifikasi intan bersertifikat Internasional, 4) memiliki tenaga profesional untuk jasa metalurgy, mineralogy dan tenaga surveyor yang terakreditasi ISO 17020, 5) pemasar jasa lain yang dimiliki Sucofindo, 6) menyediakan paket jasa terintegrasi terkait pelayanan jasa Sucofindo lainnya dan 7) memiliki hubungan dekat dengan lembaga pemerintah dan instansi pemerintah seperti KAN, Kemendag, Kemenakertrans, Kementerian ESDM.
Tinjauan Masa Depan Jasa Mineral

SBU Mineral dapat memasarkan jasanya selain menjadi sebagai surveyor pihak ketiga (third party surveyor) juga dapat menjadi sebagai surveyor pihak kedua (second party surveyor) sesuai dengan kebutuhan dan manfaat langsung bagi pelanggan saat ini dan di masa depan. Dengan sebagai surveyor pihak kedua, SBU Mineral berperan aktif secara profesional berdasarkan kompetensi yang dimiliki dalam meberikan konsultansi dan solusi bagi pelanggan dalam menyelesaikan permasalahan pelanggan.

Tabel 7. Hasil analisis kinerja faktor lingkungan eksternal makro

\begin{tabular}{|c|c|c|c|c|}
\hline Faktor Strategis & Status & Bobot & Nilai & Skor \\
\hline $\begin{array}{l}\text { Kebijakan /Regulasi pemerintah terhadap bisnis jasa mineral tentang } \\
\text { pembatasan eskpor produk mineral yang harus memiliki nilai tambah }\end{array}$ & Peluang & 0,0673 & 3,5000 & 0,2355 \\
\hline Stabilitas dan keamanan dalam negeri & Peluang & 0,0669 & 3,5000 & 0,2343 \\
\hline $\begin{array}{l}\text { Kebijakan Kementerian ESDM: peluang memasuki bisnis jasa mineral } \\
\text { tentang penetapan surveyor pelaksana penyedia jasa mineral }\end{array}$ & Peluang & 0,0651 & 3,4000 & 0,2214 \\
\hline Kebijakan KAN memeberikan akreditasi laboratorium mineral & Peluang & 0,0605 & 3,5000 & 0,2118 \\
\hline Kesadaran menggunakan lembaga surveyor nasional & Peluang & 0,0614 & 3,2000 & 0,1966 \\
\hline Stabilitas dan kondisi ekonomi dalam negeri & Peluang & 0,0638 & 3,0000 & 0,1914 \\
\hline $\begin{array}{l}\text { Kebijakan MP3EI yang mendorong pem-bangunan koridor infrastruktur } \\
\text { pertambang-an yang telah ditetapkan pemerintah }\end{array}$ & Peluang & 0,0594 & 3,2000 & 0,1901 \\
\hline Kemajuan teknologi dalam bidang pertambangan & Peluang & 0,0566 & 3,3000 & 0,1869 \\
\hline Mutu dan K3 di sektor pelayanan jasa mineral & Peluang & 0,0583 & 3,2000 & 0,1865 \\
\hline Mutu dan K3 di sektor pelayanan jasa konstruksi/infrastruktur & Peluang & 0,0582 & 3,2000 & 0,1861 \\
\hline Meluasnya akses internet untuk info jasamineral & Peluang & 0,0539 & 3,1000 & 0,1670 \\
\hline $\begin{array}{l}\text { Kebijakan manajemen pusat (head quarter) perusahaan multi nasional } \\
\text { yang mewajibkan perusahaannya di Indoensia untuk memilih lembaga } \\
\text { surveyor asing }\end{array}$ & Ancaman & 0,0564 & 2,9000 & 0,1637 \\
\hline Munculnya surveyor baru yang diakui pemerintah & Ancaman & 0,0542 & 2,8000 & 0,1518 \\
\hline Fluktuasi/unstabilnya harga komoditas pertambangan & Ancaman & 0,0628 & 2,4000 & 0,1508 \\
\hline Kebijakan pemilihan surveyor asing & Ancaman & 0,0524 & 2,8000 & 0,1468 \\
\hline Stabilitas dan kondisi perekonomian di negara lain & Ancaman & 0,0524 & 2,7000 & 0,1415 \\
\hline $\begin{array}{l}\text { Masuknya surveyor asing di Indonesia sehubungan dengan berlakunya } \\
\text { MEA }\end{array}$ & Ancaman & 0,0502 & 2,8000 & 0,1407 \\
\hline Rasio jumlah pelatihan & Kekuatan & 0,0423 & 2,7000 & 0,1141 \\
\hline $\begin{array}{l}\text { Pelatihan sesuai ruang lingkup pekerjaan karyawan dan pengembangan } \\
\text { personal }\end{array}$ & Kekuatan & 0,0429 & 2,6000 & 0,1117 \\
\hline Rasio pelanggan kontrak & Kekuatan & 0,0434 & 2,5000 & 0,1085 \\
\hline Implementasi jasa baru & Kekuatan & 0,0413 & 2,5000 & 0,1032 \\
\hline Rasio keluhan pelanggan & Kelemahan & 0,0437 & 2,0000 & 0,0874 \\
\hline Rasio pelanggan spot order & Kelemahan & 0,0444 & 1,7000 & 0,0755 \\
\hline Total atau rata-rata & & 1,0000 & 3,0882 & 3,0882 \\
\hline
\end{tabular}


Analisis Kesenjangan (Gap Analysist)

Analisis kesenjangan SBU Mineral mengacu pada kebutuhan pelanggan di masa depan, penetrasi pasar dan pengembangan dan pemasaran produk. Berdasarkan analisis matrik IE dimana posisi SBU Mineral pada kuadranII,makaperusahaaninimengetahui kesenjangan terhadap strategi yang sudah ditentukan saat ini dan masa depan. Dengan mengetahui hasil kesenjangan tersebut akan menjadi dasar dalam menentukan tujuan/ sasaran dan program bagi perusahaan. Analisis tersebut juga dapat digunakan sebagai bahan evaluasi berkala untuk kemajuan perusahaan. Hasil analisis kesenjangan yang diperoleh seperti pada Tabel 8 .

\section{Tujuan/Sasaran dan Program SBU Mineral 2016- 2020}

Berdasarkan analisis matrik IE diperoleh posisi SBU Mineral pada kuadaran II, strategi yang tepat adalah strategi intensif penetrasi pasar, pengembangan pasar dan pemasaran produk. Strategi yang sudah ditentukan digabungkan dengan analisis tinjauan masa depan industri jasa mineral dan analisis kesenjangan menjadi dasar dalam menyusun tujuan/sasaran dan program SBU Mineral lima tahun ke depan. Tujuan/sasaran dan program SBU Mineral 2016-2020 merupakan usulan perencanaan strategik untuk memperbaiki kelemahan internal, merespon kondisi lingkungan eksternal makro dan persaingan industri jasa mineral pada Tabel 9.

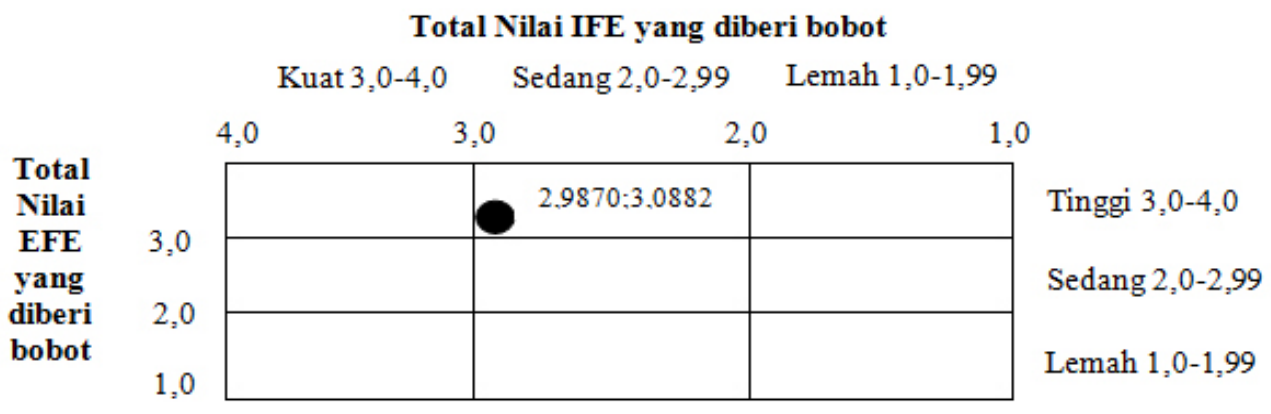

Gambar 2 Posisi SBU Mineral dalam Matriks (IE) Internal Eksternal

Tabel 8. Analisis kesenjangan SBU Mineral

\begin{tabular}{ll}
\hline \multicolumn{1}{c}{ Kondisi Saat Ini } & \multicolumn{1}{c}{ Kondisi Masa Depan (2016-2020) } \\
\hline $\begin{array}{l}\text { Penetrasi dan Pengembangan Pasar } \\
\text { Belum menetapkan fokus strategi pemasaran dan } \\
\text { segementasi pasar }\end{array}$ & $\begin{array}{l}\text { Menetapkan fokus strategi pemasaran dan segementasi } \\
\text { pasar }\end{array}$ \\
$\begin{array}{l}\text { Belum miliki penanggung jawab pemasaran } \\
\text { Pengembangan Produk }\end{array}$ & Menetapkan penangung jawab pemasaran \\
$\begin{array}{l}\text { Fokus pada posisi menjadi surveyor pihak ketiga (third } \\
\text { party surveyor) }\end{array}$ & $\begin{array}{l}\text { Mengembangkan peran menjadi surveyor pihak kedua } \\
\text { (second party) }\end{array}$ \\
$\begin{array}{l}\text { Pemasaran Produk } \\
\text { Jumlah/rasio pelanggan kontrak rendah }\end{array}$ & $\begin{array}{l}\text { Meningkatkan jumlah pelanggan kontrak } \\
\text { Implementasi jasa baru yang masih lambat }\end{array}$ \\
$\begin{array}{l}\text { Belum merespon secara memadai pandangan pelanggan } \\
\text { terhadap citra SBU Mineral sebagai penyedia jasa mineral }\end{array}$ & $\begin{array}{l}\text { Menetapkan strategi untuk meningkatkan citra SBU } \\
\text { Mineral sebagai penyedia jasa mineral dengan kapasitas } \\
\text { Internasional }\end{array}$ \\
$\begin{array}{l}\text { Belum adanya strategi atas kebijakan Pemerintah yang } \\
\text { terbuka terhadap masuknya perusahaan surveyor penyedia } \\
\text { jasa mineral asing di Indonesia }\end{array}$ & $\begin{array}{l}\text { Menetapkan strategi atas kebijakan Pemerintah guna } \\
\text { menghadapi persaingan dengan perusahaan surveyor } \\
\text { penyedia jasa mineral asing di Indonesia }\end{array}$ \\
\hline
\end{tabular}


Tabel 9. Tujuan/sasaran dan program SBU Mineral (2016-2020)

\begin{tabular}{|c|c|}
\hline Tujuan/Sasaran & Strategi dan Program \\
\hline Penetrasi pasar & $\begin{array}{l}\text { Strategi: Pendekatan dan pemasaran kepada Kementerian BUMN/ESDM/Perdagangan/ } \\
\text { Perindutrian/Pemerintah Daerah dan Asosiasi Mineral Indonesia (2016-2020) }\end{array}$ \\
\hline $\begin{array}{l}\text { Memiliki fokus strategi } \\
\text { pemasaran dan segementasi } \\
\text { pasar pada industri mineral } \\
\text { nasional dan multinasional }\end{array}$ & $\begin{array}{l}\text { Program: Membuat strategi pemasaran lima tahun ke depan dan segmentasi pasar } \\
\text { khususnya pada industri mineral nasional dan multinasional (2016) }\end{array}$ \\
\hline $\begin{array}{l}\text { Memiliki penanggung } \\
\text { jawab pemasaran }\end{array}$ & $\begin{array}{l}\text { Program: Menetapkan penanggungjawab pemasaran, bekerja sama dengan account officer } \\
\text { di Cabang SUCOFINDO(2016) dan melakukan evaluasi pe-masaran dan segementasi } \\
\text { pasar secara periodik (2016-2020) }\end{array}$ \\
\hline Pengembangan produk & $\begin{array}{l}\text { Stretegi: Melakukan pendekatan dan pemasaran kepada Kementerian ESDM/Lingkungan } \\
\text { dan Kehutanan/ Perindutrian, Himpunan Ahli Konvesi Energi(HAKE), Dewan Energi } \\
\text { Nasional (DEN) serta Asosiasi Mineral Indonesia (2016-2020) }\end{array}$ \\
\hline $\begin{array}{l}\text { Mengembangkan peran } \\
\text { menjadi surveyor pihak } \\
\text { kedua (second party) }\end{array}$ & $\begin{array}{l}\text { Program: Penunjukan penanggung jawab pengembangan dan operasional jasa konsultansi } \\
\text { mineral dan infrastruktur pertambangan serta jasa inspeksi, supervisidan pengujian batuan, } \\
\text { beton dan tanah (2016) }\end{array}$ \\
\hline Pengembangan pasar & $\begin{array}{l}\text { Strategi: Menjalankan program acara temu pelanggan, penghargaan terhadap pelanggan } \\
\text { loyal, mengaktifkan milling list pelanggan dan evaluasi pelanggan secara periodik per } \\
\text { triwulan (2016-2020) }\end{array}$ \\
\hline $\begin{array}{l}\text { Meningkatkan jumlah } \\
\text { pelanggan kontrak untuk } \\
\text { kepastian perolehan } \\
\text { pendapatan }\end{array}$ & $\begin{array}{l}\text { Program: Melakukan pendekatan kepada pelanggan spot order (jumlah pelanggan } \\
\text { dominan) SBU Mineral untuk dijadikan sebagai pelanggan kontrak pendek (durasi } 1 \\
\text { tahun) kontrak menengah (2-3 tahun) atau kontark jangka panjang/multi years } 3-5 \text { tahun } \\
(2016-2020)\end{array}$ \\
\hline $\begin{array}{l}\text { Meningkatkan upaya agar } \\
\text { implementasi jasa baru } \\
\text { meningkat }\end{array}$ & $\begin{array}{l}\text { Program:Melakukan pemasaran yang intensif dalam mengenalkan jasa-jasa mineral baru } \\
\text { yang dikembangkan agar dapat digunakan oleh pelanggan (2016--2020) }\end{array}$ \\
\hline $\begin{array}{l}\text { Menetapkan strategi untuk } \\
\text { meningkatkan citra SBU } \\
\text { Mineral sebagai penyedia } \\
\text { jasa mineral dengan } \\
\text { kapasitas Internasional }\end{array}$ & $\begin{array}{l}\text { Program: Melakukan identifikasi kriteria sebagai surveyor penyedia jasa berkapasitas } \\
\text { internasional (2016), Identifikasi mitra startegik surveyor penyedia jasa mineral asing } \\
\text { yangberoperasi diluar Indonesia untuk menjalin Kerja sama operasi (2016) serta Menjalin } \\
\text { Kerja sama operasi dengan surveyor penyedia jasa mineral asing di kawasan ASEAN } \\
\text { (2017-2018) }\end{array}$ \\
\hline $\begin{array}{l}\text { Menetapkan strategi atas } \\
\text { kebijakan pemerintah guna } \\
\text { menghadapi persaingan } \\
\text { dengan perusahaan } \\
\text { surveyor penyedia jasa } \\
\text { mineral asing yang masuk } \\
\text { ke Indonesia }\end{array}$ & $\begin{array}{l}\text { Program: Melanjutkan kerja sama yang intensif dengan Kementerian ESDM/ } \\
\text { Lingkungan dan Kehutanan /Per-industrian,Himpunan Ahli Konvesi Energi, Dewan } \\
\text { Energi Nasional,serta Asosiasi Mineral Indonesia untuk mempromosikan SBU Mineral } \\
\text { sebagai surveyor penyedia jasa bertaraf internasional (2016-2020) dan membangun } \\
\text { forum komunikasi baru dengan stakeholder pertambangan mineral tentang pentingnya } \\
\text { keberadaan perusahaan surveyor nasional penyedia jasa mineral (2016-2017) }\end{array}$ \\
\hline
\end{tabular}

\section{Implikasi Kebijakan}

Berdasarkan penetapan tujuan/sasaran dan program 2016-2020, terdapat beberapa implikasi terhadap kebijakan SBU Mineral. Implikasi kebijakan yang pertama adalah membentuk tim kajian strategi pemasaran dan segementasi pasar pada sektor industri mineral nasional dan multinasional. Kedua menetapkan penanggung jawab pengembangan dan operasional jasa mineral khususnya jasa konsultansi mineral dan infrastruktur pertambangan serta jasa inspeksi, supervisi dan pengujian batuan, beton dan tanah. Implikasi kebijakan selanjutnya menetapkan fungsi pemasaran dan penjualan (sales marketing) di cabang-cabang untuk meningkatkan pendapatan jasa mineral. Implikasi kebijakan terakhir adalah mempertimbangkan kajian kerja sama dan kemitraan dengan perusahaan penyedia jasa mineral asing yang beroperasi di luar Indonesia khususnya ASEAN dalam usaha memperoleh pengakuan dan promosi yang lebih luas. 


\section{KESIMPULAN DAN SARAN}

\section{Kesimpulan}

Aktivitas binis SBU Mineral untuk menjalankan kompetensi intinya telah sesuai dengan visi dan misi yang memenuhi empat kerangka perspektif BSC, yaitu menyediakan dan melaksanakan layanan operasional jasa mineral terakreditasi dan diakui keberadaannya oleh nasional maupun internasional.

Persaingan bisnis jasa mineral berada pada tingkat persaingan sedang. Secara internal SBU Mineral mampu mengatasi faktor kelamahannya berdasarkan faktor kekuatan yang dimilikiya dengan berada pada kategori kekuatan sedang. Untuk faktor lingkungan eksternal kemampuan merespon perubahan berada pada posisi tinggi.

Keberadaan SBU Mineral berada pada kuadran II matrik IE yaitu posisi tumbuh dan berkembang. Dengan demikian strategi yang sesuai dan dapat diterapkan untuk karakteristik unit bisnis penyedia jasa mineral adalah strategi intensif penetrasi pasar, pengembangan pasar dan pengembangan produk.

Penetapan tujuan/sasaran dan program lima tahun ke depan dapat dijadikan acuan menjadi perencanaan strategik SBU Mineral untuk menghadapi perubahan yang terjadi dan masa depan industri jasa mineral.

\section{Saran}

SBU Mineral perlu melakukan survei kepuasaan pelanggan terkait perspektif pelanggan sebagai faktor strategis paling penting (bobot 0,260 ) dengan fokus pada faktor keluhan pelanggan. Jumlah pelanggan spot order mendapatkan skor paling rendah $(0,0755)$ sebagai faktor kelemahan internal. Oleh karean itu, diperlukan upaya meningkatkan jumlah pelanggan spot order menjadi pelanggan kontrak untuk kepastian sumber pendapatan. Diperlukan penelitian lebih lanjut dengan melibatkan semua responden dari pihak eksternal yang memahami bisnis jasa mineral sehingga hasil yang diperoleh akan lebih independen.

\section{DAFTAR PUSTAKA}

Aji AA, A Satria, B Hariono.2014. Agribisnis komoditas padi dalam meningkatkan ketahanan pangan Kabupaten Jember. Jurnal Manajemen dan Agribisnis 11(1):137-145.

Atkinson H. 2006. Strategy implementation: a role for the balance scorecard. Management Decision Journal 44(10):1441-1460. http://dx.doi. org/10.1108/00251740610715740

David FR. 2011. Strategic Management ; Concep and Cases. 13th Ed. Upper Sadle River. New Jersey: Prentice Hall.

Dewi S, Syarief R, Suroso AI. 2014.Perencangan balanced scorecard untuk pengembangan strategi di SMEMEO Biotrop. Jurnal Manajemen dan Agribisnis 11(1):33-40.

Ditjen Mineral dan Batubara. 2014. Buku Saku Mineral dan Batubara. Kementerian [ESDM]; Energi Sumber Daya Mineral.

Dyah KW, Marimin, Kasutjianingati K.2015. Strategi peningkatan kualitas untuk pasar internasional melalui penerapan manajemen kualitas total: pembelajaran dari produk edamame beku. Jurnal Manajemen dan Agribisnis 12(1):36-45.

Ika S, Hubeis AV, Kuswanto S. 2012. Perancangan manajemen kinerja penyelenggaaan pendidikan dan pelatihan dengan rancangan management by objectives (MBO) dan perspektif balanced scorecard. Jurnal Manajemen dan Agribisnis 9(1): 43-58.

Ireland RD, Hoskisson RE, Hitt MA. 2008. The Management of Strategy, Concept and Cases. 10th ed. South-Western: Cengage Learning.

Jauhar S, Henny KD.2012. Daya saing dan strategi pengembangan minyak sawit di Indonesia. Jurnal Manajemen dan Agribisnis 9(3): 194-201.

Kanya LS, Rina O, Kirbarandoko. 2016. Strategi peningkatan daya saing PT 'ABCD' tbk.di industri makanan olahan pada tahun 2015. Jurnal Aplikasi Bisnis dan Manajemen 2 (1):73-82.

Kaplan SR, Norton PD. 2008. The Execution Premium:Linking Strategy to Operations for Competitive Advantage. Massachusetts: Harvard Business School Press.

Kinnear, Thomas C, Taylor, James R, 2003. Riset Pemasaran, (Terjemahan oleh Thamrin). Edisi Tiga, Jakarta: Erlangga.

Lina Y, Widyastutik. 2012. Daya saing produk turunan susu Indonesia di pasar dunia. Jurnal Manajemen dan Agribisnis 9(3):183-193.

Mandiangan S.2006.Perancangan balanced scorecard Dinas Pertanian Kabupaten Paniai [tesis]. Bogor: Institut Pertanian Bogor.

Mulyadi 2007. Sistem Terpadu Pengelolaan Kinerja 
Personel Berbasis Balanced Scorecard. Universitas Gajah Mada. Yogyakarta: STIM YKPN.

Otto Z, Daryanto HK.; Djohar S.2016. Strategi pengembangan portofolio produk divisi penerbitan buku-buku perguruan tinggi PT XYZ. Jurnal Aplikasi Bisnis dan Manajemen 2(1):83-90.

Porter ME. 2007. Strategi Bersaing (competitive strategy),(Terjemahan oleh Hendry). Tangerang: Kharisma Publishing Group.

Raymond MLB, Ine M, Iwang G.2012.Analisis pengembangan usaha pemindangan ikan di Kecamatan bekasi Barat. Jurnal Perikanan dan Kelautan 3(1):17-24.

Russel RS, Taylor BW.2013. Operation Management. New Jersey:Pearson Education, Inc. Upper Saddle River.

Sadikin K, Mangkuprawira S, Djohar S, Hermawan A.2010. Turbulensi lingkungan dalam penyusunan strategi Perusahaan: studi kasus pada perusahaan industri petrokimia. Jurnal Manajemen dan Agribisnis 7(2):159-167.

Saunders M, Mann R, Smith R. 2007. Benchmarking strategy deployment practises. Benchmarking:
An International Journal 14 (5):609-623. http:// dx.doi.org/ 10.1108/ 14635770710819281.

Suhartoyo, Fahmi I, Beik IS. 2015. Perencanaan dan eksekusi strategi penyaluran dana tabungan perumahan pegawai negeri sipil di BapertarumPNS.Jurnal Aplikasi Bisnis dan Manajemen 1(1): 46-55. https://doi.org/10.17358/JABM.1.1.46.

Suswono, Daryanto A, Sawit MH, Arifin B. 2009. Strategi peningkatan daya saing Perum Bulog. Jurnal Manajemen dan Agribisnis 6(2):91-108.

Thompson dan Strickland. 2006. Strategy, Winning In The Market Place Core Concepts, Analytical Tools, Cases. Boston-Mc Graw Hill Irwin.

Ward J, Peppard J. 2002. Strategic Planning for Information Systems. West Sussex: John Wiley \& Sons Limited, 42.

Wheelen, Hunger JD. 2006. Strategic Management and Business Policy. 10th Ed. USA: Pearson Prentice Hall, Inc.

Widyastutik, Reni KA.2013. Strategi kebijakan mutu dan standar produk ekspor dalam meningkatkan daya saing (studi kasus produk ekspor biji kakao). Jurnal Manajemen dan Agribisnis 10(2): 98-108. 